\title{
Review
}

\section{Urine therapy briefing for scientists}

\author{
Kook-Hee Kang \\ Senior Research Fellow, ReSEAT Program, Korea Institute of Science and Technology information, 66, Hoegi-ro, Dongdaemun-gu, \\ Seoul, 130-741, Republic of Korea
}

\begin{abstract}
Urine is a gift of God for the health of human being in proverbs of the Old Testament in Hindu. Urine therapy (UT) is not a mysterious folk remedy, it is doctor's examined prescription based on modern science and UT is recommended strongly with absolute confidence. It is effective and amazing to a number of incurables such as chronic fatigue, lingering, a cold, nose allergy, diabetes, high blood pressure, and gout. Also, UT is applied not only for human beings but also for animals, the latter including amazing effects for pigs and cows. The purpose of this manuscript is to help change the misunderstandings of urine and UT and to help reader realize it is one of the helpful alternative remedies.
\end{abstract}

Keywords Urine therapy, traditional medicine, public health, stockbreeding application

\section{INTRODUCTION}

Urine is a gift of God for the health of human beings in Proverbs of the Old Testament 5:15; Revelation of the New Testament 22:17; Phrases 107 in the Mahabharata of the Hindu religion. Urine therapy (UT) is not a mysterious folk remedy. It is the prescription examined by doctor based on modern science in many countries. The first record for the diagnostic and therapeutic approaches of urine was considered from India, and exist in many other regions such as Tibet, Mexico, Australia, China, Egypt, Greece, and ancient Rome (Savica et al., 2011) Especially after the work of Dr. Armstrong, a physician in England (Amstrong, 1944), many scientists are interested in UT such as Japanese physician Nakao who wrote "The Miracle of Urine Therapy" Makino Publishing Co., Japan, and surgeon Dr. Sano, Korean physicians Dr. Seong and Dr. Lee who wrote "Urine Therapy," Chaekwabut Publishing co., Korea. They recommended strongly UT with absolute confidence (Kang, 1998). Human urine is just like the engine oil of an automobile and lubricant of a machine. It is effective in the prevention of diseases for healthy people and recovery for patients. Therefore, human urine is a biomedicine that is pollution free. As a remedy, it is effective and amazing to incurable issues such as chronic fatigue, a cold, nasal allergies, diabetes, high blood pressure, heart disease, arthritis, pimples, skin disease, constipation, athlete's foot, venereal diseases, women's diseases, leprosy, tuberculosis, leukemia, spinal cancer, hepatic cancer, larynx cancer, pancreas cancer, colony cancer, blood cancer, kidney cancer, colitis, nephritis, pyorrhea alveolaris, alveolitis, digestive trouble, duodenitis, hepatitis, hemorrhoids, burns, eruptions by food poisoning, pain in the shoulders and waist, migraines and gout. (Christy, 1994) Furthermore, UT is applied not only for human beings but also on animals. It shows amazing effects in the swine and cattle industries as suggested in "The Book of Abstracts-Second World Conference on Urine Therapy" and "The Abstracts of

\footnotetext{
*Correspondence: Kook-Hee Kang

E-mail: kauthead@gmail.com

Received August 22, 2012; Accepted November 21, 2012; Published

Novemver 30, 2012

doi: http://dx.doi.org/10.5667/tang.2012.0033

(C)2012 by Association of Humanitas Medicine

TANG / www.e-tang.org
}

4th World Conference on Urine Therapy." and reported in research papers of Awale et al. (2006) and Jain et al. (2010).

UT has a long history in the world. It has been written in the Hindu and Buddhist scriptures in detail thousands of years ago. Also, in Korea, the famous scholar Hur Joon presented UT in his medical book "Donguibogam" 500 years ago, which is listed on the UNESCO culture index. More recently John Armstrong from the UK and Dr. Ryoichi Nakao from Japan, both medical doctors who have studied modern medicine, strongly prescribe UT in their books 'The Water of Life' and 'From Cold to Cancer' respectively. These days UT is being promoted as an important alternative medicine in Korea. (Kang, 1998)

\section{Conferences of UT}

The former Prime Minister Desai of India in 1977, a nation of over 700 million people, was interviewed by the New York Times in 1981 and stated that he drank a cup of urine for health in the morning for breakfast instead of eating a meal. He became a world hero for UT and participants at the triennial world conferences conduct a prayer for him at those meetings. I think he lived his life with a high spirit and courage. He was 99 when he died. After this interview, the world became interested in UT with several world conferences.

The first world conference was held in Goa, India in 1996 Over 600 participants from 40 countries attended. It was appropriate that the first UT conference was held in India due to India's long history and practice of UT. After the first world conference was held in India, the renewed interest in UT gathered significant momentum around the world. The 2nd Conference was held in Germany in 1999 and was published in The Book of Abstracts-Second World Conference on Urine Therapy, Germany. Dr. Nakao, former Chairman of the Japan Doctors' Association, also presented a key lecture on the miracle of the untold story of UT (Savica et al., 2011). Many doctors also presented their testimonials with UT they used to cure chronic illnesses (Christy, 1994). At this conference UT was approved by medical science. I also attended this conference and gave a lecture on the application of UT at a pig farm (Kang, 1998). The pork quality from feeding urine had been improved to a higher grade. Also Carmen Thomas, who was a famous announcer for a radio station in Germany, 
collected numerous testimonials about urine mania on UT during many years and published a book in 1992. This book was published in 34 editions in 4 years and sold over 1 million copies as of 1999. She is well known to the people of Germany. The 3rd Conference was held in Brazil 2003 and was very successful. Dr. Fatima, the chairman of the conference, is a medical doctor. The 4th world conference on UT was held in Korea and resulted in the "The Abstracts of 4th World Conference on Urine Therapy" in 2006. Over 300 attendees from 20 countries joined us for the conference. The 5th conference was held at Mexico and was made into a CD in November 2009.

\section{Applications of UT}

For a nation's military forces, urine is an important resource for survival during emergency conditions, such as confinement by an enemy or isolation from others when food and drink are not available. Even worse is the critical loneliness such as created by a natural disaster when help is not available. Lieutenant General Ryu, former Commanding General, Republic of Korea Army Training Headquarters, understands that in a critical emergency a soldier using UT could survive a disaster compared to other soldiers uninformed about UT. It has been reported that the US Army has made urine a key ingredient soldiers should know when using rehydrated meals. A BBC news report of July 22, 2004 states, "The US military has devised a way to ensure its troops in battle need never go hungry - with dried food that can be rehydrated using dirty water or URINE.' In the absence of water, urine could be used. Although the last statement mentions 'long term it would cause kidney damage.' However, there is no evidence that this statement is true. In fact, long term drinking of one's own urine does not cause any damage, but aids in tissue reformation. (Kang, 1998)

Peoples are living in a modern era, but natural disasters are occurring at an alarming rate. They may find themselves in unknown circumstances such as a sudden natural disaster, an earthquake, a volcanic eruption, a tsunami, or an accident. When they find themselves in an emergency situation, the urine may just be their life water. It is seen in survival stories of individuals in collapsed buildings, buried alive in coal or gold mines or lost at sea for days only to survive their ordeal by drinking their own urine. That is a testament to the life-giving properties of urine.

In the 21 st century, there are still numerous varieties of incurable illnesses such as cancers, pandemic flu, AIDS, obesity, skin diseases, constipation, melancholy and tinnitus. There is no way by conventional medicines to cure them for complete healing, rapid healing, healing without pain, and healing without cost. Therefore, many of us are looking for traditional and natural therapies such as urine as a cure. UT is really convenient to use. Urine is produced by one's own body. It can be used free anytime and anywhere when needed. Actually, it is being confused with much false medical information such as the swine flu scare 'false pandemic' led by the WHO and drug firms (Kang, 1998). With the overflow of medical misinformation, it is believed that UT can keep one happy and free from the fear syndrome. The Sun News of Jan 11,2010 tells us that the swine flu outbreak was a 'false pandemic,' said Wolfgang Wodarg, head of health at the Council of Europe January 8, 2010. That was great news but remember the fear that people might have suffered due to the misinformation. Also, remember the added precautions taken in public areas, especially at airports, when travelling from one country to another. The USA recently destroyed $\$ 250$ million worth of swine flu vaccinations due to a projected expiration date to permit newer vaccines to be created by the medical pharmaceutical companies.

Thousands of people are suffering every day from AIDS, malaria, allergies, pandemic flu, etc. Whether they would be infected or not, depends on their immune system. If someone's immune system is fully activated, any kinds of illnesses will be recovered. One's own urine definitely helps improve one's immune system activation (Kang, 1998)

In this century obesity is a global problem. Obesity does not discriminate on race, gender or age. Fortunately, UT is very helpful to decrease weight without any side effects. Obesity in the USA is a big problem as shown on this slide. Young people who would love to serve their nation in the US Armed Forces would not be accepted if they were obese.

UT has a lot of testimonials and medical-based evidence. However, it has been embedded in our minds that urine is a waste product and dirty to touch with our hands. Babies from birth as they grow into childhood have been repeatedly told that urine is dirty, filthy and they shouldn't touch it or get it on them. What is needed is reeducation of the human race on the content and properties of urine. Urine is 'Algoboni,' the water of life, suggested by Dr. Armstrong in 1944 and as he says, 'your own perfect medicine.' (Amstrong, 1944; Kang, 1998)

Humans have been nurtured by three kinds of bio waters (Kang, 1998):

1) Amniotic fluid for nurturing the fetus;

2) Mother's milk for baby after birth;

3) Urine for our adult immune system.

These life waters are all natural substances and not commercially produced by humans. Of course commercial products are used such as:

1) Incubators at hospitals for early delivery of the fetus;

2) Powdered milk for babies produced by food companies;

3)Medicines from pharmaceutical companies through hospitals and pharmacies.

But commercial products could be impossible to compare with the natural properties of herbs and other alternative practices that cure ailments that modern medicine cannot yet answer.

\section{UT in modern times}

Urine is really a clean liquid produced by our bodies and by nano-sized filters in the kidneys. Urine is clearer than blood. Actually, there are no dirty components in urine. They are all nutrients, enzymes, minerals, antioxidants, antibodies, bioactive substances, etc. and all good for one's health. Some medicines contain elements extracted and purified from urine that are used in hospitals as commercial products. Urine from cattle and horses is used in the manufacturing of medicines for human consumption (Awale et al., 2006; Jain et al., 2010).

In the hospital, people hope for recovery as soon as possible without pain. But modern medicine is not always successful in curing all illnesses. UT, however, heals a variety of common illnesses without pain or cost. In fact, there are repeated testimonies from many people who stated that they enjoyed rapid healing and complete healing from UT; the recovery that they had hoped for when they initially went to the hospital for modern medical treatment. If one has an accident such as a bone fracture or some other ailment that needs surgery, then urgently go to the doctor or hospital. However, using UT may well cure other illnesses that have not been cured through modern medical practices. Urine is usually thought dirty and UT may be heard that the ridicule from others saying, 'UGH, your using your urine, that's nasty!' In addition 
to urine's effectiveness, little do these people know that UT is a way to cure an illness rapidly, completely, without pain and it provides one's own immune liquid (Kang, 1998).

For astronauts, water is life. In this photo, they are talking with NASA control center. It was reported that they drink recycled and filtered urine because the urine is dirty. But, there is no reason to filter urine because urine is clean. By filtering the urine, they have eliminated a lot of the enzymes, elements, and bioactive substances in the recycled urine. Reeducation about the benefits of unfiltered UT for astronauts is necessary as soon as possible.

\section{CONCLUSION}

I have been fortunate to hear first-hand testimonies from people who have been cured from a variety of common illnesses and many incurable diseases without money and/or conventional medicines. I have experienced the complete curing of my own troubles-chronic fatigue, athlete's foot, dry eyes, common colds, paradentitis and a facial malady my wife experienced. How is urine active to cure varieties of illnesses? Urine is not a drug, but an extraordinary natural healing liquid that contains substances produced by one's own body that modern medical science has proven to be one of the most powerful and natural medicines known to man. Urine has a miracle function as the healing activities to run the acceleration of blood circulation and enhancement of the immune system. Therefore, UT should be strongly recommended for all humans.

\section{CONFLICT OF INTEREST}

The author has no conflicting financial interests.

\section{REFERENCES}

Armstrong J.W. A treatise on urine therapy. $1^{\text {st }}$ ed. (Essex, England: The C.W.Daniel Co.Ltd), 1944.

Awale S, Linn TZ, Than MM, Thet MM, Swe T, Saiki I, Kadota S. An amazing cow's urine therapy practice in Myanmar. J Tradit Med. 2006;23:178-183.

Christy M M. Your Own Perfect Medicine. $2^{\text {nd }}$ ed. (Arizona, USA: Wishland Inc.), 1994.

Jain NK, Gupta VB, Garg R, Silawat N. Efficacy of cow urine therapy on various cancer patients in Mandsaur District, India A survey. IJGP, 2010;4:29-35.

Kang KH. Algoboni-The water of life. (Seoul, Korea: Sungkyunkwan Univ. Press; Bermagui, Australia: Harald W. Tietze Publishing Pty. Ltd.), 1998.

Savica V, Calò LA, Santoro D, Monardo P, Mallamace A, Bellinghieri G. Urine therapy through the centuries. J Nephrol. 2011;17:S123-S125. 